\title{
Determinan Kualitas Tidur Mahasiswa Kampus A di Universitas Muhammadiyah Prof DR Hamka
}

\section{Determinants of Sleep Quality for Campus A Students at Muhammadiyah University Prof DR Hamka}

Julia Tristianingsih ${ }^{1}$, Sarah Handayani ${ }^{1}$

${ }^{1}$ Program Studi Kesehatan Masyarakat Fakultas Ilmu-ilmu Kesehatan, Universitas Muhammadiyah Prof. DR. Hamka Jakarta

*Korespondensi penulis: sarah_handayani@uhamka.ac.id

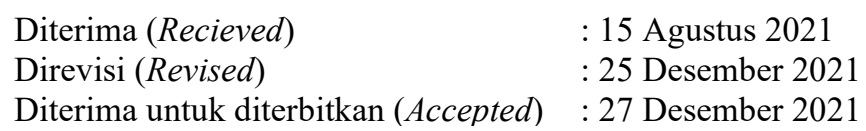

Diterima (Recieved)

Direvisi (Revised)

: 15 Agustus 2021

: 25 Desember 2021

Diterima untuk diterbitkan (Accepted) $\quad: 27$ Desember 2021

\begin{abstract}
ABSTRAK
Latar Belakang. Tidur yang berkualitas adalah kebutuhan dasar manusia namun pada mahasiswa kebutuhan tidur akan terganggu karena tugas sebagai mahasiswa dan gaya hidup yang berubah. Apabila kualitas tidur tidak terpenuhi atau mengalami gangguan berpengaruh pada menurunnya kualitas hidup seseorang serta menurunnya fungsi kesehatan.

Tujuan. untuk mengetahui faktor-faktor yang berhubungan dengan kualitas tidur pada mahasiswa Kampus A Universitas Muhammadiyah Prof. Dr. Hamka tahun 2020

Metode. Penelitian ini menggunakan desain cross sectional dengan teknik pengambilan sampel proportional stratified random sampling. Populasi penelitian ialah seluruh mahasiswa Kampus A UHAMKA dengan sampel 117 mahasiswa. Data yang digunakan ialah data primer dengan menggunakan kuesioner. Analisis data menggunakan uji chi-square.

Hasil. Hasil penelitian menunjukkan bahwa terdapat 69 orang (59\%) responden yang memiliki kualitas tidur buruk. Terdapat hubungan penggunaan gawai $(\mathrm{p}=0,001)$, aktivitas fisik $(\mathrm{p}=0,001)$, dan stres $(\mathrm{p}=0,001)$ dengan kualitas tidur. Sedangkan tidak ada hubungan antara jenis kelamin $(\mathrm{p}=0,313)$ dengan kualitas tidur.

Kesimpulan. Kualitas tidur mahasiswa kampus A di Universitas Muhammadiyah Prof DR Hamka berkaitan dengan penggunaan gawai, aktifitas fisik serta stres.
\end{abstract}

Kata Kunci: kualitas tidur, aktivitas fisik, stres

\section{ABSTRACT}

Background. Quality sleep is a basic human need, but in college students, sleep will be disrupted due to student duties and changing lifestyles. If the quality of sleep is not fulfilled or a disturbance, it will affect the decrease in a person's quality of life and decrease the health function.

Objective to determine the factors related to sleep quality in Campus A students University Muhammadiyah Prof. Dr. Hamka in 2020.

Method. This study used a cross-sectional design with a proportional stratified random sampling technique. The study population was students of Campus A UHAMKA with a sample of 117 students. The data used are primary data using a questionnaire. Data analysis used the chi-square test.

Results. The results showed that there were 69 people (59\%) of respondents who had poor sleep quality. There is a relationship between the use of gadgets ( $p=0.001)$, physical activity $(p=0.001)$, and stress $(p=0.001)$ with sleep quality. Meanwhile, there was no relationship between gender $(p=0.313)$ and sleep quality.

Conclusion. The sleep quality of campus A students at the University of Muhammadiyah Prof DR Hamka is related to the use of gadgets, physical activity and stress.

Keywords: sleep quality, physical activity, stress 


\section{LATAR BELAKANG}

Tidur merupakan perilaku kesehatan yang sangat penting namun sering diabaikan. Kesehatan tidur yang buruk adalah masalah global. Stranges et al. ${ }^{1}$ memperkirakan bahwa, jumlah orang dewasa dengan masalah tidur di negaranegara berpenghasilan rendah akan meningkat dari 150 juta pada tahun 2010 menjadi 260 juta pada tahun 2030.

Colten dalam Perry et al. ${ }^{2}$ mengatakan bahwa tidur merupakan komponen kesehatan yang sangat esensi, dimana waktu, durasi dan kualitas tidur merupakan determinan yang penting untuk kesehatan. Lebih lanjut, Siegel dalam dalam Perry et al. ${ }^{2}$ mengatakan bahwa tidur memainkan peran penting dalam regulasi metabolisme, regulasi emosi, kinerja, konsolidasi memori, proses penyembuhan otak, dan pembelajaran. Berbagai penelitian lain menyatakan bahwa kurang tidur dapat menyebabkan penyakit kronis, seperti obesitas, penyakit kardiovaskular, dan diabetes. ${ }^{3,4,5}$ Kurang tidur juga dapat menyebabkan depresi, gangguan mood, dan penurunan kinerja kognitif, termasuk memori dan kesulitan belajar. ${ }^{6,7,8}$ Karena pentingnya fungsi-fungsi ini, tidur harus dipandang sama pentingnya dengan kesehatan. Namun, praktisi kesehatan masyarakat dan penyedia layanan kesehatan lainnya belum memusatkan perhatian besar pada pentingnya tidur bagi kesehatan. ${ }^{1}$

Promosi kesehatan tidur melibatkan peningkatan durasi dan kualitas tidur. ${ }^{9}$ Istirahat dan tidur sama pentingnya dengan kebutuhan dasar lain. Tidur merupakan hal yang esensial bagi kesehatan. ${ }^{10}$ Manfaat tidur akan terasa ketika seseorang sudah mencapai tidur yang berkualitas. Kualitas tidur merupakan kepuasan seseorang terhadap tidur sehingga orang tersebut tidak merasa lelah, gelisah dan mudah terangsang, apatis dan lesuh, kehitaman di sekitar mata, kelopak mata bengkak, sakit kepala, sering menguap dan mudah mengantuk, mata perih. Kualitas tidur juga diartikan sebagai suatu keadaan tidur yang dijalani seorang individu menghasilkan kesegaran dan kebugaran saat terbangun. ${ }^{11}$

Kualitas tidur seseorang dapat dipengaruhi oleh beberapa faktor, diantaranya stres, gaya hidup dan kebiasaan, dan aktivitas fisik. ${ }^{12}$ Kualitas tidur meliputi aspek kuantitatif (jam tidur) dan kualitatif (kedalaman tidur), seperti lamanya tidur, waktu yang diperlukan untuk bisa tertidur, frekuensi terbangun dan aspek subjektif seperti kedalaman dan kepulasan tidur. Kualitas tidur dikatakan baik jika tidak menunjukkan tanda-tanda kurang tidur dan tidak mengalami masalah dalam tidur. ${ }^{11}$

Kondisi kurang tidur banyak ditemui dikalangan dewasa muda terutama mahasiswa. ${ }^{13}$ Mahasiswa adalah elit masyarakat yang mempunyai nilai lebih dibandingkan masyarkat pada umumnya, karena tingkat pendidikan yang relitif tinggi memberikan kesempatan untuk berfikir kritis dan objektif dalam menghadapi masalah yang terdapat di masyarakat. ${ }^{14}$ Tugas dan perkembangan mahasiswa dalam fase dewasa muda dapat tercapai dan mencapai titik maksimal ketika mahasiswa terpenuhi kebutuhan dasarnya. Manusia dalam memenuhi kebutuhan hidupnya melakukan penyusunan prioritas dari yang paling penting hingga yang tidak penting dan dari yang mudah hingga yang sulit untuk dicapai. ${ }^{15}$ Urutan lima tingkat kebutuhan manusia yaitu kebutuhan dasar (fisiologis), kebutuhan akan keselamatan, kebutuhan akan cinta, kebutuhan akan harga diri, dan kebutuhan akan aktualisasi diri. ${ }^{15}$ Kebutuhan fisiologis adalah kebutuhan dasar yang paling penting dan esensial. Apabila kebutuhan ini tidak terpenuhi maka dapat memengaruhi kebutuhan yang lain. Kebutuhan fisiologis pada manusia terdiri dari hygiene, nutrisi, tidur, kenyamanan, terbebas dari nyeri, oksigenasi, dan eliminasi. ${ }^{15}$

Berdasarkan hasil penelitian yang telah dilakukan pada mahasiswa di Universitas Negeri Yogyakarta, didapatkan hasil sebanyak 79 mahasiswa $(71,8 \%)$ memiliki kualitas tidur buruk sedangkan sebanyak 31 mahasiswa $(28,2 \%)$ memiliki kualitas tidur baik. ${ }^{16}$ Hasil penelitian tersebut sejalan dengan penelitian yang dilakukan oleh Hastuti et al. ${ }^{17}$ didapatkan hasil sebanyak 139 mahasiswa (79\%) dengan kualitas tidur buruk dan sebanyak 37 mahasiswa (21\%) dengan kualitas tidur baik. Berdasarkan hasil wawancara singkat yang dilakukan pada bulan April 2020 kepada 30 mahasiswa Kampus A Universitas Muhammadiyah Prof. Dr. Hamka, didapatkan bahwa 24 mahasiswa mengeluh pola tidurnya tidak teratur, terbangun dengan keadaan tidak bugar dan segar, dan mengantuk di siang 
hari. Penelitian ini berujuan untuk mengetahui faktor-faktor yang berhubungan dengan kualitas tidur pada mahasiswa Kampus A Universitas Muhammadiyah Prof. Dr. Hamka Jakarta.

\section{METODE}

Penelitian ini merupakan penelitian survei analitik dengan meggunakan pendekatan cross sectional. Pada penelitian ini variabel independen yaitu penggunaan gadget, aktivitas fisik, stres, dan jenis kelamin. Sedangkan variabel dependen yaitu kualitas tidur. Populasi dalam penelitian ini adalah seluruh mahasiswa Kampus A Universitas Muhammadiyah Prof. Dr. Hamka Jakarta yang berjumlah 14.075 mahasiswa pada tahun 2020. Sampel dalam penelitian ini adalah sebesar 117 mahasiswa Kampus A Universitas Muhammadiyah Prof. Dr. Hamka Jakarta. Teknik pengambilan sampel yang dilakukan dengan metode Stratified Random Sampling. Teknik pengumpulan data yang dilakukan menggunakan kuesioner dengan memberikan sejumlah pertanyaan atau pernyataan kepada responden melalui google form. Analisis data dalam penelitian ini adalah univariat dan bivariat. Penelitian ini sudah disetujui melalui Komisi Etik Universitas Muhammadiyah Prof. Dr. Hamka.

\section{HASIL}

Berdasarkan Tabel 1, kualitas tidur responden dikelompokkan menjadi kualitas tidur buruk jika skor $>5$ dan kualitas tidur baik jika skor $\leq 5$. Responden memiliki kualitas tidur buruk yaitu 69 orang (59\%). Sebagian besar responden ialah mahasiswa perempuan sebanyak 55,6\%. Responden dengan tingkat penggunaan gawai tinggi sebanyak $64,9 \%$, rendah dalam melakukan aktivitas fisik sebanyak $59 \%$, dan paling banyak responden mengalami stres sedang sejumlah $28,2 \%$.

Berdasarkan Tabel 2, hasil uji bivariat variabel kulitas tidur pada mahasiswa dengan penggunaan gawai menunjukkan nilai $p$ value $=0,001$ yang artinya bahwa terdapat hubungan yang signifikan antara penggunaan gawai dengan kualitas tidur. Selain itu, didapatkan nilai $\mathrm{PR}=11,868(3,979-35,403)$ yang menunjukkan bahwa responden dengan tingkat penggunaan gawai tinggi lebih berisiko mengalami kualitas tidur yang buruk. Pada hubungan antara variabel kulitas tidur pada mahasiswa dengan aktivitas fisik menghasilkan nilai $p$-value $=0,001$ yang artinya bahwa terdapat hubungan yang signifikan antara aktivitas fisik dengan kualitas tidur. Untuk nilai PR adalah 3,304 (2,001-5,458) yang menunjukkan bahwa responden yang beraktivitas fisik kurang aktif mempunyai kecenderungan untuk mengalami kualitas tidur buruk. Hubungan antara variabel kulitas tidur pada mahasiswa dengan stres mendapatkan nilai $p$-value $=0,001$ yang artinya bahwa terdapat hubungan yang signifikan antara stres dengan kualitas tidur. Pada nilai PR menunjukkan 1,651 (1,205-2,261) yang berarti bahwa responden yang mengalami stres tinggi lebih berisiko memiliki kualitas tidur buruk. Pada variabel jenis kelamin $p$-value $=$ 0,313 yang berarti tidak berhubungan antara kualitas tidur dengan jenis kelamin.

Tabel 1. Gambaran Kualitas Tidur Variabel Independen Mahasiswa Kampus A Uhamka

\begin{tabular}{lcc}
\hline \multicolumn{1}{c}{ Variabel } & Jumlah & Persentase (\%) \\
\hline Kualitas Tidur & & \\
Buruk & 69 & 59 \\
Baik & 48 & 41 \\
Jenis Kelamin & & \\
perempuan & 65 & 55,6 \\
Laki-laki & 52 & 44,4 \\
Penggunaan Gawai & \\
Tinggi & 76 & 64,9 \\
Rendah & 41 & 35 \\
Aktivitas Fisik & & \\
Tinggi & 27 & 23,1 \\
Sedang & 21 & 17,9 \\
Rendah & 69 & 59 \\
Stres & & \\
Normal & 38 & 32,5 \\
Ringan & 24 & 20,5 \\
Sedang & 33 & 28,2 \\
Berat & 15 & 12,8 \\
Sangat Berat & 7 & 6,0 \\
\hline
\end{tabular}


Tabel 2. Faktor-faktor yang Berhubungan dengan Kualitas Tidur pada Mahasiswa Kampus A Uhamka

\begin{tabular}{|c|c|c|c|c|c|c|c|c|}
\hline \multirow{3}{*}{ Variabel } & \multicolumn{6}{|c|}{ Kualitas Tidur } & \multirow{3}{*}{$\begin{array}{c}\text { PR } \\
(95 \% \mathrm{CI})\end{array}$} & \multirow{3}{*}{ nilai-P* } \\
\hline & \multicolumn{2}{|c|}{ Buruk } & \multicolumn{2}{|c|}{ Baik } & \multicolumn{2}{|c|}{ Total } & & \\
\hline & $\mathbf{n}$ & $\%$ & $\mathbf{n}$ & $\%$ & $\mathbf{n}$ & $\%$ & & \\
\hline \multicolumn{9}{|l|}{ Jenis Kelamin } \\
\hline Perempuan & 41 & 63,1 & 24 & 36,9 & 65 & 100 & \multirow{2}{*}{$\begin{array}{c}1,171 \\
(0,857-1,602)\end{array}$} & \multirow{2}{*}{0,313} \\
\hline Laki-laki & 28 & 53,8 & 24 & 46,2 & 52 & 100 & & \\
\hline \multicolumn{9}{|c|}{ Penggunaan Gawai } \\
\hline Tinggi & 66 & 86,8 & 10 & 13,2 & 76 & 100 & \multirow{2}{*}{$\begin{array}{c}11,868 \\
(3,979-35,403)\end{array}$} & \multirow{2}{*}{0,001} \\
\hline Rendah & 3 & 7,3 & 38 & 92,7 & 41 & 100 & & \\
\hline \multicolumn{9}{|l|}{ Aktivitas Fisik } \\
\hline Kurang Aktif & 57 & 82,6 & 12 & 17,4 & 69 & 100 & \multirow{3}{*}{$\begin{array}{c}3,304 \\
(2,001-5,458)\end{array}$} & \multirow{2}{*}{0,001} \\
\hline Aktif & 12 & 25 & 36 & 75 & 48 & 100 & & \\
\hline \multicolumn{8}{|l|}{ Stres } & \\
\hline Tinggi & 41 & 74,5 & 14 & 25,5 & 55 & 100 & 1,651 & \multirow{2}{*}{0,001} \\
\hline Rendah & 28 & 45,2 & 34 & 54,8 & 62 & 100 & $(1,205-2,261)$ & \\
\hline
\end{tabular}

\section{PEMBAHASAN}

Penelitian pada mahasiswa Kampus A Uhamka Jakarta Tahun 2020 ini, diperoleh bahwa sebagian besar responden yaitu 59\% memiliki kualitas tidur buruk. Hasil penelitian ini sesuai dengan penelitian yang dilakukan Hastuti et al. ${ }^{17}$ didapatkan hasil sebanyak 139 mahasiswa (79\%) dengan kualitas tidur buruk dan sebanyak 37 mahasiswa (21\%) dengan kualitas tidur baik. Mahasiswa cenderung memiliki kualitas tidur singkat dan jam tidur yang lebih larut dibandingkan dengan kelompok populasi lain. ${ }^{18}$ Kualitas tidur pada mahasiswa melibatkan beberapa dimensi, diantaranya adalah latensi tidur, durasi tidur dan disfungsi siang hari. ${ }^{19}$ Pada latensi tidur, penggunaan gawai saat malam hari pada mahasiswa dapat memperpanjang waktu durasi latensi tidur hingga lebih dari 30 menit. $^{19}$ Durasi tidur pada usia dewasa muda 7-9 jam setiap malam dapat dikatakan memiliki kualitas tidur yang baik. ${ }^{19}$ Tetapi responden tidur setiap harinya sekitar 3-6 jam bahkan terdapat responden yang tidur $\geq 9$ jam. Untuk disfungsi di siang hari, keadaan mahasiswa di siang hari cenderung tidak bersemangat dan mengantuk. $^{19}$

Pada variabel penggunaan gawai didapatkan adanya hubungan yang signifikan antara penggunaan gawai dengan kualitas tidur. Penggunaan gawai pada mahasiswa akan terus meningkat karena gawai sudah menjadi suatu kebutuhan serta memiliki tujuan dan fungsi praktis untuk pekerjaan mahasiswa. ${ }^{20}$
Hastuti et al. ${ }^{17}$ menyatakan ada hubungan positif yang cukup signifikan antara intensitas penggunaan gawai dengan kualitas tidur pada mahasiswa. Penelitian oleh Nowreen dan Ahad $^{21}$ juga menyatakan terdapat hubungan yang signifikan antara penggunaan gawai dengan kualitas tidur. Temuan serupa oleh Keswara et al. ${ }^{22}$ yang menyatakan ada hubungan signifikan antara perilaku penggunaan gawai dengan kualitas tidur.

Ketergantungan pada gawai mengakibatkan mahasiswa sering lupa waktu dan melakukan aktivitas penggunaan gawai hingga larut malam misalnya mengerjakan tugas hingga larut malam atau tidak ingin ketinggalan berita orang lain di media sosial. Ketergantungan pada gawai juga dapat dilihat dari beberapa faktor, yaitu daily life disturbance, artinya dampak negatif yang timbul akibat penggunaan gadget dan hal ini dirasakan langsung oleh pengguna gawai. ${ }^{23}$ Positive anticipantion, artinya perasaan gembira saat menggunakan gawai dan merasa kosong saat tidak menggunakannya. ${ }^{23}$ Withdrawl, tidak sabaran saat tidak menggunakan gadget dan perasaan kesal ketika diganggu saat menggunakan gadget. ${ }^{23}$ Cyberspace-oriented relationship, hubungan dengan seseorang yang diperoleh melalui teknologi gadget. ${ }^{23}$ Overuse, mengacu pada penggunaan gawai yang tidak terkontrol. ${ }^{23}$

Penggunaan gawai dalam waktu lama khususnya pada malam hari akan menimbulkan kesulitan untuk tidur. Hal tersebut karena cahaya pada gawai menyerupai cahaya 
pada siang hari yang dapat menghambat mekanisme irama sirkadian (jam biologis). ${ }^{19}$ Guna mendapatkan kualitas tidur baik penggunaan gawai sebelum tidur dapat dilakukan setidaknya satu jam sebelum tidur. Kondisi pre-sleep membutuhkan waktu selama 10 sampai 30 menit. Jika waktu per-sleep digunakan untuk menggunakan gawai maka waktu pre-sleep akan lebih dari 30 menit. $^{24}$ Kegiatan tersebut dapat digantikan dengan membaca buku atau berinteraksi dengan keluarga.

Pada variabel aktivitas fisik, didapatkan hasil adanya hubungan yang signifikan antara aktivitas fisik dengan kualitas tidur. Hasil serupa ditunjukkan pada penelitian yang dilakukan oleh Iqbal ${ }^{16}$ menyatakan ada hubungan signifikan antara aktivitas fisik dengan kualitas tidur $(p<0,05)$ dan responden yang aktif dalam beraktivitas fisik mempunyai peluang mendapatkan kualitas tidur yang baik 4,136 kali lebih tinggi dibandingkan dengan responden yang tidak aktif dalam beraktivitas fisik. Penelitian oleh Baso et al. ${ }^{25}$ juga menyatakan terdapat hubungan yang positif antara aktivitas fisik dengan kualitas tidur dan responden dengan aktivitas fisik cukup berpeluang 2,5 kali lebih besar untuk mendapatkan kualitas tidur yang baik.

Aktivitas fisik tidak hanya meningkatkan konsentrasi, produktivitas, dan kualitas emosi, namun juga dapat meningkatkan kualitas tidur seseorang. Seseorang dengan aktivitas fisik menengah (moderate) biasanya memperoleh tidur yang mengistirahatkan, khususnya kelelahan akibat kerja atau latihan yang menyenangkan. Akan tetapi, aktivitas fisik yang berlebihan akibat kerja yang meletihkan akan membuat seseorang sulit tidur. ${ }^{12}$ Seseorang dengan aktivitas fisik kurang aktif, dapat memulai aktivitas fisik dari bangun tidur, dengan gerakan ringan pada tangan, kaki, kepala, merenggangkan badan ke samping kanan dan kiri, membungkuk, mengangkat satu persatu kaki, tekuk, dan posisi seperti mencium lutut. Setelah tubuh merasa rileks dapat melanjutkan aktivitas seperti jalan sehat 30 sampai 60 menit, bersepeda, renang, atau lari di tempat selama 30 menit. $^{26}$

Pada variabel stres, didapatkan bahwa adanya hubungan yang signifikan antara tingkat stres dengan kualitas tidur pada mahasiswa. Penelitian ini sejalan dengan Hendi Aryadi et al. ${ }^{27}$ menyatakan ada hubungan yang signifikan antara tingkat stres mahasiswa dengan kualitas tidur. Ratnaningtyas dan Fitriani $^{28}$ juga menyatakan ada hubungan antara stres dengan kualitas tidur pada mahasiswa $(\mathrm{p}<0.05)$. Hasil serupa dinyatakan oleh Palayukan (2020) yang menyatakan adanya hubungan stres emosional dengan kualitas tidur mahasiswa.

Terdapat faktor individu dan sosial yang menjadi penyebab stres pada mahasiswa. Sumber stres di dalam diri seseorang, muncul ketika seseorang menilai kekuatan motivasional dalam menghadapi konflik serta kurang bisa memahami dan menyikapi konflik dengan baik. Sumber stres di dalam keluarga, seperti perselisihan, perasaan saling acuh tak acuh, memiliki tujuan yang berbeda. Sumber stres di dalam lingkungan, seperti lingkungan fisik (kebisingan dan suhu), kecelakaan, dan beban mata kuliah. ${ }^{29}$

Stres emosional menyebabkan seseorang menjadi tegang dan sering kali frustasi apabila tidur. Stres juga menyebabkan seseorang mencoba terlalu keras untuk tidur, sering terbangun selama siklus tidur, atau terlalu banyak tidur. Stres yang berlanjut dapat menyebabkan seseorang memiliki kebiasaan tidur buruk. $^{12}$ Pada saat stres terjadi peningkatan pada hormon epinefrin, norepinefrin, dan kortisol yang mempengaruhi susunan saraf pusat sehingga menimbulkan keadaan terjaga. Selain itu perubahan hormon tersebut juga mempengaruhi siklus tidur Rapid Eye Movement (REM) dan Non-Rapid Eye Movement (NREM). Hal ini membuat orang terbangun pada malam hari dan bermimpi buruk. $^{30}$

Adapun pada variabel jenis kelamin, didapatkan bahwa tidak adanya hubungan antara jenis kelamin dengan kualitas tidur. Hal ini sesuai dengan penelitian Hendika ${ }^{31}$, yang menyatakan tidak terdapat hubungan antara jenis kelamin dengan kualitas tidur. Hasil analisis oleh Yip et al. ${ }^{32}$ juga menyatakan tidak terdapat hubungan antara jenis kelamin dengan kualitas tidur, namun secara deskriptif perempuan lebih banyak mengalami kualitas 
tidur buruk (611 responden) dan perempuan lebih besar berpeluang mengalami kualitas tidur buruk (95\% CI 41.95-49.45\%).

Perempuan lebih mungkin mengalami kualitas tidur buruk daripada laki-laki. Hal tersebut dapat disebabkan oleh karena turunnya kadar hormon estrogen dan progesteron selama siklus menstruasi. ${ }^{33}$ Penurunan kadar progesteron selama masa premenstruasi berhubungan dengan kesulitan tidur dan meningkatkan frekuensi bangun. Hormon estrogen dapat menurunkan latensi tidur dan frekuensi bangun serta meningkatkan jumlah total tidur. Kualitas tidur buruk pada perempuan juga dapat disebabkan karena kelelahan, ketidaknyamanan yang membuat sulit tidur, serta pekerjaan dapat membuat seseorang sulit tertidur. Terdapat banyak perubahan dalam perilaku dan lingkungan yang harus dilakukan agar wanita mengalami kualitas tidur baik, seperti mengatasi suhu kamar tidur, mengatur pencahayaan, menghindari kafein di sore hari, tidak mengkonsumsi makanan berat sebelum tidur, dan belajar cara mengatasi stres dan kecemasan. $^{34,35,36}$

\section{KESIMPULAN}

Terdapat hubungan yang signifikan antara kualitas tidur dengan penggunaan gawai, aktivitas fisik, dan stres. Tidak terdapat hubungan antara jenis kelamin dengan kualitas tidur.

\section{SARAN}

Mahasiswa perlu memperhatikan kebutuhan tubuh akan tidur mengingat banyak mahasiswa yang memiliki kualitas tidur buruk. Mahasiswa diharapkan dapat mengenal gangguan-gangguan tidur yang dialami terkait dengan kualitas tidur yang buruk. Perlu dilakukan penjadwalan tidur yang baik, pengaturan aktivitas, manajemen stres yang baik, serta pengontrolan waktu penggunaan gawai agar mahasiswa memperoleh kualitas tidur yang baik. Kualitas tidur yang baik dapat mempengaruhi kesegaran, semangat, dan performa mahasiswa dalam melaksanakan kegiatannya sehari-hari.

\section{UCAPAN TERIMA KASIH}

Penulis mengucapkan terima kasih kepada semua pihak yang telah berkontribusi dalam menyelesaikan artikel ini.

\section{DAFTAR REFERENSI}

1. Stranges S, Tigbe W, Gómez-Olivé FX, Thorogood M, Kandala NB. Sleep problems: an emerging global epidemic? Findings from the INDEPTH WHO-SAGE study among more than 40,000 older adults from 8 countries across Africa and Asia. Sleep. 2012;35(8):1173-1181. doi:10.5665/sleep.2012

2. Perry GS, Patil SP, Presley-Cantrell LR. Raising Awareness of Sleep as a Healthy Behavior. Prev Chronic Dis 2013;10:130081. doi: 10.5888/pcd10.130081

3. Cappuccio FP, Taggart FM, Kandala NB, et al. Meta-analysis of short sleep duration and obesity in children and adults. Sleep. 2008;31(5):619-626.

doi:10.1093/sleep/31.5.619

4. Cappuccio FP, Cooper D, D'Elia L, Strazzullo P, Miller MA. Sleep duration predicts cardiovascular outcomes: a systematic review and meta-analysis of prospective studies. Eur Heart $J$. 2011;32(12):1484-1492.

doi:10.1093/eurheartj/ehr007

5. Cappuccio FP, D'Elia L, Strazzullo P, Miller MA. Quantity and quality of sleep and incidence of type 2 diabetes: a systematic review and metaanalysis. Diabetes Care. 2010;33(2):414420. doi:10.2337/dc09-1124

6. Li L, Wu C, Gan Y, Qu X, Lu Z. Insomnia and the risk of depression: a meta-analysis of prospective cohort studies. BMC Psychiatry. 2016;16(1):375. doi:10.1186/s12888-016-1075-3

7. Goldstein A.N., Walker M.P. The role of sleep in emotional brain function. Annu. Rev. Clin. Psychol. 2014;10:679-708. doi: 10.1146/annurev-clinpsy-032813153716.

8. Lo J., Groeger J.A., Cheng G.H., Dijk D.J., Chee M. Self-reported sleep duration and cognitive performance in older adults: A systematic review and meta- 
analysis. Sleep $\quad$ Med. 2016;17:87-98. doi: 10.1016/j.sleep.2015.08.021.

9. Albakri U, Drotos E, Meertens R. Sleep Health Promotion Interventions and Their Effectiveness: An Umbrella Review. Int $J$ Environ Res Public Health. 2021;18(11):5533. doi:10.3390/ijerph18115533

10. Asmadi. 2012. Teknik Prosedural Konsep Dan Aplikasi Kebutuhan Dasar Klien. Jakarta: Salemba Medika.

11. Sugiono, Wisnu Wijayanto Putro, and Sylvie Indah Kartika Sari. 2018. Ergonomi Untuk Pemula: (Prinsip Dasar \& Aplikasinya). 1st ed. Malang: USB Press.

12. Potter, and Perry. 2014. Fundamental Keperawatan, Edisi 7. Jakarta: EGC.

13. Hidayat, A. A. 2014. Pengantar Kebutuhan Dasar Manusia, Edisi 2. Jakarta: Salemba Medika.

14. Afkari, Rafiuddin, and Ismail Suardi Wekke. 2018. Intelektualisme Mahasiswa Islam: Sejarah Dan Kontribusi Terhadap Gerakan Islam Indonesia. Yogyakarta: Deepublish.

15. Asmadi. 2012. Teknik Prosedural Konsep Dan Aplikasi Kebutuhan Dasar Klien. Jakarta: Salemba Medika.

16. Iqbal, Muhammad Dien. 2017. "Hubungan Aktivitas Fisik Dengan Kualitas Tidur Mahasiswa Perantau Di Yogyakarta." Universitas Negeri Yogyakarta.

17. Hastuti, Desi Tri, Dwi Budi Prastiani, and Khodijah. 2019. "Hubungan Intensitas Penggunaan Smartphone Dengan Kualitas Tidur Mahasiswa Program Studi Sarjana Keperawatan Stikes Bhamada Slawi." JITK 10(1):73-78.

18. Blank, Yelena. 2015. "The Effects of Changes in Sleep Schedule Variability on First-Year College Students." ProQuest Dissertations and Theses 82.

19. Prasadja, Andreas. 2009. Ayo Bangun! Dengan Bugar Karena Tidur Yang Benar. 2nd ed. edited by Rahman. Jakarta Selatan: PT Mizan Publika.

20. Iswidharmanjaya, Derry. 2014. Bila Si Kecil Bermain Gadget Volume 1. Bandung: Bisakimia.

21. Nowreen, Nida, and Farhana Ahad. 2018. "Effect of Smartphone Usage on Quality of
Sleep in Medical Students." National Journal of Physiology, Pharmacy and Pharmacology 8(10):4-9.

22. Keswara, Umi Romayati, Novrita Syuhada, and Wahid Tri Wahyudi. 2019. "Perilaku Penggunaan Gadget Dengan Kualitas Tidur Pada Remaja." Jurnal Kesehatan 13(3):233-39.

23. Kwon, Min, Dai-jin Kim, Hyun Cho, and Soo Yang. 2013. "The Smartphone Addiction Scale : Development and Validation of a Short Version for Adolescents." 8(12):1-7.

24. Jarmi, Armaya, and Sri Intan Rahayuningsih. 2017. "HUBUNGAN PENGGUNAAN GADGET DENGAN KUALITAS TIDUR PADA REMAJA." Jurnal Ilmiah Mahasiswa Fakultas Keperawatan 2(3).

25. Baso, Miranda C., Fima L. F. G. Langi, and Sekplin A. S. Sekeon. 2018. "Hubungan Antara Aktivitas Fisik Dengan Kualitas Tidur Pada Remaja Di SMA Negeri 9 Manado." Jurnal KESMAS 7(5):5-10.

26. Hanifah, Erma. 2011. Cara Hidup Sehat. Jakarta: PT.Sarana Bangun Pustaka

27. Hendi Aryadi, I. Putu, I. Gusti Agung Ayu Andra Yusari, Ida Ayu Dewi Dhyani, I. Putu Eka Kusmadana, and Putu Gde Sudira. 2018. "Korelasi Kualitas Tidur Terhadap Tingkat Depresi, Cemas, Dan Stres Mahasiswa Kedokteran Universitas Udayana Bali." Callosum Neurology $1(1): 20-31$.

28. Ratnaningtyas, Tri Okta, and Dwi Fitriani. 2019. "Hubungan Stres Dengan Kualitas Tidur Pada Mahasiswa Tingkat Akhir." Edu Masda Journal 3(2):181-91.

29. Nugraheni, Hermien, Tri Wiyatini, and Irmanita Wiradona. 2018. Kesehatan Masyarakat Dalam Determinan Sosial Budaya. Yogyakarta: Deepublish.

30. Sherwood, Lauralee. 2011. Fisiologi Manusia Edisi6. Jakarta: EGC.

31. Hendika, Indah Putri. 2019. "Hubungan Karakteristik Mahasiswa Dengan Kualitas Tidur Mahasiswa Tahap Akademik Program Studi Kedokteran Universitas Andalas." Universitas Andalas.

32. Yip, Tiffany, Yuen Mi Cheon, Yijie Wang, Wen Qin Deng, and Amber Levanon 
Seligson. 2020. "Sociodemographic and Environmental Factors Associated with Childhood Sleep Duration." Sleep Health: Journal of the National Sleep Foundation 000:1-11.

33. Rodrigues, Tiago, De Lima Diego, and Augusto Santos. 2018. "Association of Sleep Quality with Sociodemographic Factors and Lifestyle in Adolescents from Southern Brazil." World Journal of Pediatrics (0123456789).

34. Lingga, Lanny. 2012. Program AntiX Tanpa Obat. Jakarta: Gramedia.

35. Sharp, Timothy J. 2011. Happiness Is Now: Hanya 10 Langkah Untuk Lebih Sehat Dan Bahagia. Australia: Finch Publishing.

36. Sugani, Surya, and Lucia Priandarini. 2010. Cara Cerdas: UntukSehat. Jakarta: TransMedia. 